\title{
Development of China volleyball research time series research
}

\author{
Hongliang Yang, Zhifen Jian, Qian Yang and Bing Zhang ${ }^{a}$ \\ Institute of Physical Education, Huanggang Normal University, Huangzhou 438000, China
}

\begin{abstract}
Volleyball research paper is the volleyball lovers, volleyball the crystallization of scientific research workers mental work, in particular those published in the journal article about sports is more advanced and authority. This article through to between 2008 and 2013 research papers on volleyball, carries on the analysis, sorting and statistics, summarized its number and the corresponding college for time series analysis. Which shows the present situation of volleyball development in our country, and then optimize the volleyball management, make the training more high-level volleyball athletes in our country.
\end{abstract}

\section{Introduction}

Volleyball as one of Chinese developed "Three big balls" events, its development status always attracts broadly masses attentions, in international range, "Volleyball, football, basketball" are rapidly moving forward, compare with international advanced countries, Chinese volleyball development speed is relative slower, although there are some historical reasons, mainly is still that masses lack of recognition of volleyball.

In Chinese volleyball development process, it has ever got certain achievements, from which glorious ones include Chinese women volleyball obtained "five consecutive championships", it propelled Chinese volleyball competitive level to a higher level. But in Sydney Olympic Games, Chinese women volleyball team lost top three, while Chinese men's volleyball team even hadn't qualified to competition, which let Chinese volleyball to come to trough. We analyze its causes that mainly because Chinese present volleyball population declines sharply, no qualified reserve talent to inherit volleyball undertakings development. Relative volleyball scientific research papers are crystallization of volleyball enthusiasts, volleyball scientific researchers' brain works, are understanding and summary of volleyball from these people in learning and working. Mainly these articles that published in relative sports periodicals, they have more forwardness and authority. It also can be supposed that China relative sports core journals are important media in Chinese experiences and academic exchanging, are also important parts to spread volleyball relative knowledge and thrive and exploit sports science. [1-5]

With respect to this, the paper makes time series analysis [6, 7] by analyzing, sorting and making statistics of relative volleyball scientific research papers from 2008 to 2013 as

\footnotetext{
$\overline{{ }^{a} \text { Corresponding author: tiyuxi@qq.com }}$
}

well as summarizing their amount and corresponding institutions. Among them, it indicates Chinese volleyball development status and features and rules of published relative volleyball scientific papers, well summarizes them in the hope of providing good theoretical support for Chinese future developing volleyball event.

\section{Model establishment}

The paper's analysis of time series is listing events change situations according to chronological orders and then constructing an analytical time series. We make effective observation and researches on time series, find out its corresponding change and development rules, predict its future trend that is corresponding time series analysis.

\subsection{Stationary sequence modeling}

(1) Modeling steps:

According to Chinese relative volleyball papers number in sports core journals in six years from 2008 to 2013 as initial data, it lists following flow. Model recognition: as Table 1.

Table 1. Basic principle.

\begin{tabular}{|c|c|c|}
\hline$\hat{\rho}_{k}$ & $\hat{\Phi}_{k k}$ & Select model \\
\hline Tailing & P order tailing & $\operatorname{AR}(\mathrm{p})$ \\
\hline q order tailing & Tailing & $\operatorname{MA}(\mathrm{q})$ \\
\hline Tailing & Tailing & $\operatorname{ARMA}(\mathrm{p}, \mathrm{q})$ \\
\hline
\end{tabular}

\subsection{Non-stationary sequence modeling}

Firstly, it needs to do stationary operation on data, and furthermore we establish ARIMA (p, q) model to solve the 
process, model structure usage occasion is difference stationary sequence fitting: $\left\{\begin{array}{l}\Phi(B) \nabla^{d} x_{t}=\Theta(B) \varepsilon_{t} \\ E\left(\varepsilon_{t}\right)=0, \operatorname{Var}\left(\varepsilon_{t}\right)=\sigma_{\varepsilon}^{2}, E\left(\varepsilon_{t} \varepsilon_{s}\right)=0, s \neq t \\ E x_{s} \varepsilon_{t}=0, \forall s<t\end{array}\right.$

\section{Model application and corresponding data processing}

According to China published single authored, co-authored papers published numbers in six years from 2008 to 2013; Correspond to above data; it draws "black-white bar chart" as Fig.1.

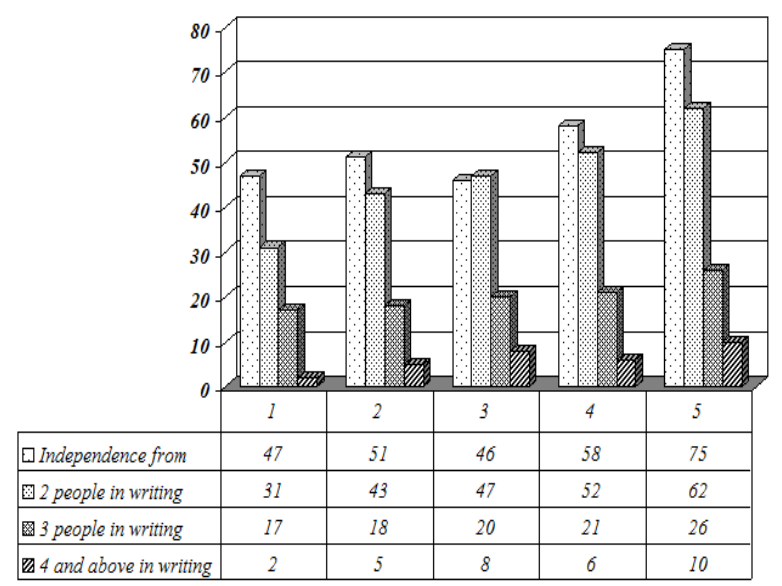

Figure 1. From alone in writing published papers about volleyball.

Correspond to above Fig.1, horizontal coordinate 1 represents data in 2008.2 represents data in 2009.3 represents data in 2010.4 represents data in 2011.5 represents data in 2013. Due to data statistics missing, it cannot make statistics of papers writing status in2012, so it doesn't make statistics of 2012 this time, but it has little impacts on final analysis, we can ignore its data.

To sum up, it can get following conclusion: single authored relative volleyball scientific researching papers numbers are obviously higher than that of co-authored, and it belongs to fluctuate and rising trend, while co-authored relative volleyball scientific research papers numbers are in steady rising. Correspond to above each journal or magazine corresponding time changes.

From above data, we can see that maximum proportion in volleyball event published numbers of sports core journals is "Journal of Beijing University of Physical Education that is $18.03 \%$.Secondly is "Chinese sports science and technology" that occupies $14.75 \%$ of totality. Least proportion is "Journal of sports medicine" only occupies $0.55 \%$ of totality.

Decompose time series data; it is clear tendency pink line, circulation or seasonal green line, stochastic blue line, as following Fig.2: The decomposition of the time series data contrast figure.

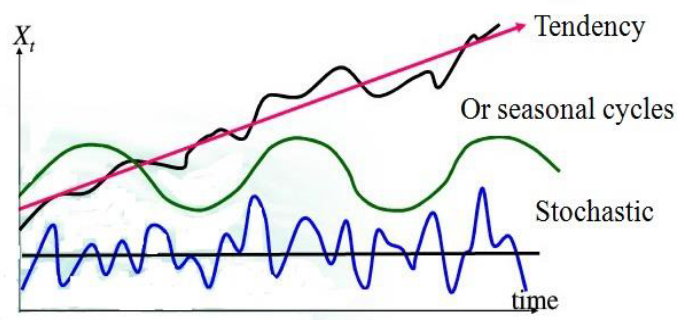

Figure 2. The decomposition of the time series data contrast figure.

According to Figure 5 and combine with Figure 4, we can see China's each core journals published relative volleyball event scientific papers are mostly in the declining tendency.

\section{Conclusion}

By above time series analysis result, we can see that China's each core journals published relative volleyball event scientific papers are mostly in the declining tendency. With respect to this, we summarize Chinese volleyball system sustainable system result optimization and get Figure 6 System structure for the sustainable development of volleyball in our country, from which it corresponds. By practical series analysis of Chinese sports core journals published relative volleyball scientific papers, it gets presently Chinese volleyball development is not going well, is entirely in the declining tendency. Correspond to Chinese volleyball development status, it summarizes Chinese volleyball system sustainable development system, optimizes management structure, vigorously publishes relevant volleyball event core papers, cultivates reserve talents with attainments, let national people to understand volleyball and like volleyball so that can promote Chinese volleyball overall level.

\section{References}

1. C. F. Sun and X. Y. Yang, Journal of Xiaogan University, 23, 36-39(2003).

2. H. X. Feng and Y. C. Huang, Journal of Nanjing Institute of Physical Education: Natural Science, 6, 23-25(2007).

3. S. H. Cao, Journal of Beijing Union University, 5, 75-80(1991).

4. X. P. Ren, Journal of Zhejiang Normal University Natural Sciences, 35, 226-230(2012).

5. W. Jiang, Journal of Nanjing Institute of Physical Education: Natural Science, 10, 48-51(2011).

6. J. W. Lee and S. C. Park, Journal of Coastal Research, 32, 213-224(2015).

7. X. J. Ma, W. Wang, N. Li, X. J. Song and H. B. Xu, Journal of Mechanical Engineering Research and Developments, 38, 12-17(2015). 